Artigo original

Hegemonia - Revista Eletrônica de Relações Internacionais do Centro Universitário Unieuro

ISSN: 1809-1261

UNIEURO, Brasília, número 7, 2011, pp. 52-72.

Recebido em: 18/10/2010

Revisado em: 23/11/2010

Aprovado em: 25/12/2010

\title{
Políticas Públicas para Populações Tradicionais: reflexões sobre a prática antropológica em espaços governamentais
}

Lima, Ludmila Moreira ${ }^{1}$

Resumo: Com base em duas experiências de trabalho envolvendo a prática antropológica fora do espaço acadêmico e dentro do campo governamental, propomos uma reflexão sobre a ampliação do fazer antropológico quando relacionado ao desenvolvimento de políticas públicas. Assim, o nosso objetivo é o de avaliar de que modo o capital teórico-conceitual-metodológico produzido no campo da Antropologia pode ser útil no sentido de enriquecer e problematizar processos e ações, pela incorporação de novos instrumentos de análise e pela revelação de dimensões esquecidas pelos agentes governamentais.

Palavras-chave: Políticas públicas, cooperação, participação

Abstract: Based on two experiences of work involving the anthropological pratice outside the academic and within the government, we reflect on the expansion of anthropological making when related to the development of public policies. Thus, our goal is to evaluate how the notional and conceptual and methodological framework produced in the field of anthropology may be useful to enrich and problematize processes and actions through the incorporation of new analytical tools and the revelation of forgotten dimensions by government officials.

Key-wods: public policies, cooperation, participation

1 Doutora em Antropologia. Professora do Centro Universitário de Brasília Uniceub. 
Artigo original

Hegemonia - Revista Eletrônica de Relações Internacionais do Centro Universitário Unieuro

ISSN: 1809-1261

UNIEURO, Brasília, número 7, 2011, pp. 52-72.

\section{I ntrodução}

Este artigo pretende contribuir para a reflexão sobre certas experiências de trabalho que, nas últimas décadas, no Brasil, vêm mobilizando cada vez mais os antropólogos: a implementação de políticas públicas em diversos níveis de governo e em atividades que envolvem parcerias entre instituições estatais, organizações da sociedade civil e agências de cooperação internacional.

Nesse sentido e com o foco em dois projetos governamentais destinados respectivamente às populações indígenas e extrativistas no contexto da Amazônia brasileira, tendo como horizonte a construção participativa do desenvolvimento sustentável, proponho uma reflexão sobre as inserções que tive nesses processos, na qualidade de consultora em antropologia: primeiro, no "Projeto de Proteção às Populações e Terras Indígenas da Amazônia LegalPPTAL", que é parte de um programa maior denominado "Programa Piloto para a Proteção das Florestas Tropicais do Brasil-PP-G7"; em seguida, no âmbito da pesquisa "Mapeamento das Populações Extrativistas da Amazônia Legal", realizado pela Coordenadoria do Agroextrativismo, ligada à Secretaria de Coordenação da Amazônia, do Ministério do Meio Ambiente-MMA, com a parceria do Instituto Socioambiental-ISA.

Durante um período de três anos, pude aproximar-me dessas experiências de trabalho, como consultora em antropologia, em relação ao projeto destinado às populações indígenas, e como coordenadora de uma pesquisa sobre os grupos extrativistas da Amazônia, que deu suporte ao referido mapeamento. Não se pretende aqui verificar se esses projetos tiveram êxito em seus 
Artigo original

Hegemonia - Revista Eletrônica de Relações Internacionais do Centro Universitário Unieuro

ISSN: 1809-1261

UNIEURO, Brasília, número 7, 2011, pp. 52-72.

propósitos primordiais, mas tão somente analisar o alcance das ações empreendidas em meio aos obstáculos surgidos no processo de sua execução para, por fim, contribuir para a avaliação dos caminhos percorridos e dificuldades enfrentadas pelos antropólogos, quando inseridos profissionalmente no contexto de políticas públicas, projetos governamentais e interinstitucionais e em programas de cooperação internacional.

\section{Sobre o “Programa Piloto para a Proteção das Florestas Tropicais do Brasil- PPG-7"}

O “Programa Piloto para a Proteção das Florestas Tropicais do Brasil-PP-G7" é um programa articulado de proteção às florestas Amazônica e Atlântica, que começou a ser negociado entre o governo brasileiro e o grupo de países integrantes do G7 no ano de 1990, tornando-se efetivo em 1992. Desde sua concepção, o Programa foi apresentado como uma ação conjunta envolvendo o governo - nos níveis federal, estadual e municipal - a sociedade civil brasileira e a comunidade internacional que, por meio de subprogramas e projetos participativos, buscaria maximizar os benefícios ambientais das florestas, tendo como foco as necessidades das populações locais e os objetivos do desenvolvimento sustentável. Cabe ressaltar o caráter piloto do Programa, destinado a testar, experimentar e aprender a respeito de novas formas de proteger as florestas e promover o seu uso sustentado. Buscava-se fundamentalmente reunir esforços envolvendo mobilização para criação de políticas públicas, legislação, regulamentações e incentivos os mais diversos - e conjugar ações 
Artigo original

Hegemonia - Revista Eletrônica de Relações Internacionais do Centro Universitário Unieuro

ISSN: 1809-1261

UNIEURO, Brasília, número 7, 2011, pp. 52-72.

participativas para a descoberta dos caminhos que gradativamente levariam ao desenvolvimento sustentável.

Sobre o "Projeto Integrado de Proteção às Populações e Terras I ndígenas da Amazônia Legal- PPTAL"

Em 1992, a convite da Comissão de Coordenação do Programa Piloto, a Fundação Nacional do Índio-FUNAl elaborou a proposta de um componente indígena a ser integrado às ações do PP-G7. Nesse momento, ficou acordado que os recursos seriam disponibilizados principalmente para a regularização fundiária, na medida em que se julgava ser esta providência essencial e primordial para a defesa do patrimônio natural e cultural das comunidades indígenas. Nascia, portanto, o desenho inicial do PPTAL após uma série de negociações que se estenderam até 1995, quando foram assinados os contratos de contribuição financeira com os organismos dos países financiadores.

O PPTAL definiu como objetivo central concluir a regularização das terras indígenas da Amazônia Legal - conforme o estabelecido na Constituição Brasileira de 1988 - e fez do processo regulatório o seu próprio alicerce, ou componente fundamental. Sua organização incluiu, além do componente "Regularização Fundiária", os componentes "Vigilância e Fiscalização"; "Estudos e Capacitação em Terras Indígenas" e "Gerenciamento do Projeto".

Executado pela FUNAl e coordenado por uma unidade de gerenciamento ligada diretamente à Presidência do órgão, denominada Coordenação Técnica do PPTAL - CTPPTAL, o Projeto reuniu profissionais de distintas formações contratados pelo Programa das Nações Unidas para o Desenvolvimento-PNUD para 
Artigo original

Hegemonia - Revista Eletrônica de Relações Internacionais do Centro Universitário Unieuro

ISSN: 1809-1261

UNIEURO, Brasília, número 7, 2011, pp. 52-72.

atuarem em uma gerência administrativa e uma gerência técnica e assim colaborarem, com a FUNAI, no desenvolvimento do Projeto.

Conheci o PPTAL por motivos profissionais. Devido à minha formação em antropologia, fui convidada a integrar a equipe de técnicos e consultores contratados e lotados na gerência técnica da CTPPTAL e, nessa condição, atuar na implementação do Projeto, sob um contrato de trabalho de vigência inicial de um ano, em seguida prorrogado por mais seis meses. Essa experiência motivou, posteriormente, a realização de minha pesquisa de doutorado em Antropologia Social.

Cabe lembrar que, desde a concepção do PPTAL e durante o seu desenvolvimento, foram previstas e estabelecidas várias parcerias entre diversas organizações e associações indígenas, organizações não governamentais, instituições e órgãos públicos, entidades e organismos internacionais, com o objetivo de materializar um espaço de planejamento, de decisões e de controle transparente e democrático para a execução do Projeto. Se, por um lado, esse esforço otimizou seu desempenho, por outro, produziu disputas, redundância de ações, entraves burocráticos, enfim, conflitos de distintas naturezas a mobilizar os agentes em torno de objetos que os faziam polemizar desde a dimensão prático-operacional até a questão da soberania do Estado e as relações de poder estabelecidas no eixo Norte-Sul.

Em suma, havia uma população a ser beneficiada por um Projeto com dotações financeiras suficientes para dar conta dos objetivos traçados. Havia uma determinação constitucional exigindo a demarcação das terras indígenas da Amazônia no prazo máximo de cinco anos, a contar da data da promulgação da Constituição. Mas, entre a população indígena e os objetivos do Projeto, foi criada uma unidade de gerenciamento, ou a Coordenação Técnica do PPTAL - 
Artigo original

Hegemonia - Revista Eletrônica de Relações Internacionais do Centro Universitário Unieuro

ISSN: 1809-1261

UNIEURO, Brasília, número 7, 2011, pp. 52-72.

CTPPTAL e designada a FUNAI como mediadoras e executoras das ações previstas. Isso sem falar nos diversos agentes institucionais MMA, ABC, Banco Mundial, KFW, GTZ, PNUD, CPC, ONGs e associações indígenas ${ }^{2}$ - envolvidos na implementação do Projeto, cujas inserções e ingerências, dependendo do papel de cada instituição, eram diretas ou indiretas, permanentes ou pontuais.

Atuando como técnica e consultora no processo de implementação do Projeto, percebi ali temas passíveis de serem reconstruídos como problemas de pesquisa. Assim, as preocupações primordiais que me levaram, posteriormente, ao objeto de estudo de minha pesquisa de doutorado foram as relações de poder e as formas de resistência e de conflito surgidas como respostas ao impacto ${ }^{3}$ decorrente da execução do PPTAL pela FUNAI, incluindo, nesse processo, o campo de parcerias configurado para a consolidação das metas do Projeto.

Todavia, no calor da luta, isto é, no percurso cotidiano da consultoria e imersa nas ações do Projeto, meu lugar de fala, ainda que referido à minha formação em antropologia, colocava-me diante dos imperativos da gestão e não da pesquisa sobre as singularidades

2 MMA: Ministério do Meio Ambiente; ABC: Agência Brasileira de Cooperação KFW: Kreditanstalt Für Wiederaufbau/Agência Alemã de Cooperação Financeira; GTZ: Deutsche Gesellschaft für Technische Zusammenarbeit/Agência Alemã de Cooperação Técnica; PNUD/UNDP: Programa das Nações Unidas para o Desenvolvimento; CPC: Comissão Paritária Consultiva. ONG's: ISA/Instituto Socioambiental; CTI: Centro de Trabalho Indigenista; Amigos da Terra. Associações Indígenas: FOIRN: Federação das Organizações Indígenas do Rio Negro; UNI-Acre: União das Nações Indígenas do Acre; OPIMP: Organização dos Povos Indígenas do Médio Purus, entre outras.

3 Utilizo o temo impacto inspirando-me na própria representação construída sobre o Projeto, qual seja: a de que ele representaria algo novo e impactante, em termos de objetivos e proposta de atuação. Esse pressuposto traz implícita a idéia da mudança de um contexto pré-existente, bem como desperta, em termos analíticos, o interesse de se buscar entender até que ponto e em que níveis transformações foram efetuadas e também possibilitadas, haja vista a articulação do Projeto a um campo extremamente denso - em termos de ideário e ideologias e diverso - em termos da multiplicidade de atores a ele relacionados. 
Artigo original

Hegemonia - Revista Eletrônica de Relações Internacionais do Centro Universitário Unieuro

ISSN: 1809-1261

UNIEURO, Brasília, número 7, 2011, pp. 52-72.

que o Projeto produziu. É certo que fiquei freqüentemente tentada a mergulhar no campo do simbólico, a procurar os caminhos camuflados ou explícitos de exercício de poder, a refletir mais sobre o processo e menos sobre os produtos - relatórios, propostas, etc que devia formular e encaminhar. Todavia, a linguagem da gestão de um projeto é a linguagem da intervenção; o tempo é regido por prazos e agendas, ainda que haja o compromisso de não se prejudicarem interesses e direitos adquiridos por aqueles que geralmente são o alvo das ações executadas.

Em relação ao que vivenciei, como consultora e antropóloga, antes de tudo e na busca de resolver meus próprios impasses, optei por buscar compreender o campo em que havia me inserido, reconstruindo eventos, fatos, relações e experiências à luz do que me foi ensinado pela Antropologia. Assim, foi possível observar, algum tempo depois de minha inserção na Coordenação do Projeto, que o PPTAL na FUNAI e todos os seus parceiros produziram um encontro que gerou um espaço de lutas singular, na medida em que desencadearam, no nível das interações cotidianas, conflitos de diversas naturezas, muitos dos quais naturalizados como inerentes a todo e qualquer ambiente de trabalho.

Todavia, para além de impasses institucionais, gerenciais, operacionais e técnicos apontados como centrais para o entendimento e enfrentamento dos problemas desencadeados na execução do PPTAL, outras dimensões mereciam ser trabalhadas, como, por exemplo: os conflitos que se configuraram pelo agenciamento das parcerias constituídas para a concretização do Projeto e que deram visibilidade a difícil tarefa do gerenciamento da pluralidade e da alteridade. Ou, como acentua Clegg (1996), os mecanismos e as linguagens de poder postos em ação naquele 
Artigo original

Hegemonia - Revista Eletrônica de Relações Internacionais do Centro Universitário Unieuro

ISSN: 1809-1261

UNIEURO, Brasília, número 7, 2011, pp. 52-72.

contexto em que se configuraram identidades e espaços nitidamente demarcados.

Como os atores envolvidos percebiam e construíam suas distinções - nos mais diversos níveis em que elas surgiam - e por que freqüentemente elas desencadeavam conflitos que comprometiam o desenvolvimento do objeto planejado? Por que e a partir de quais premissas se formulava a idéia de uma cultura administrativa tipicamente nacional e local - com referência à FUNAI - em choque com outros padrões postos em contato através de ONGs e agências de cooperação internacional? Por que certas distinções, em certos contextos, se expressam hierarquicamente? Por que um Projeto fortemente influenciado e mobilizado pela cultura da participação não conseguia criar espaços verdadeiros de interlocução com os seus beneficiários?

Nesse sentido, embora atuando como consultora, procurei, na medida do possível, observar, compreender as múltiplas relações, falas, práticas e ritos institucionais e os múltiplos interesses em jogo com os quais me confrontava cotidianamente. A compreensão do funcionamento desse campo de relações contribuía para diluir parte da tensão produzida por um trabalho e contexto orientados pela interlocução, mas pontuado pela intervenção. Contexto em que se configurou um nós supostamente idêntico, posto que delineado por um objetivo comum - o de contribuir para a proteção das populações indígenas da Amazônia e para a construção do desenvolvimento sustentável - e, simultaneamente, um nós feito de inúmeros outros diferenciados a partir de diversos níveis de agenciamentos humanos que ele propiciou, pois foi principalmente por meio deles que várias modalidades de conflitos foram construídas e mantidas.

Em relação ao Projeto, como muitos supunham, é possível que grande parte dos problemas estivesse relacionado a fatores 
Artigo original

Hegemonia - Revista Eletrônica de Relações Internacionais do Centro Universitário Unieuro

ISSN: 1809-1261

UNIEURO, Brasília, número 7, 2011, pp. 52-72.

gerenciais, às qualidades e perfis organizacionais dos agentes institucionais envolvidos e à forma como se buscou engendrar o diálogo entre eles. Destaco, por exemplo, a insuficiente articulação entre a CTPPTAL e os departamentos da FUNAI, responsáveis pela execução de seu componente fundamental, o da regularização fundiária. Outro fator que veio dificultar o gerenciamento do Projeto referia-se à capacidade técnica e administrativa tanto da FUNAl quanto da CTPPTAL, ambas insuficientes para fazer frente e gerar respostas satisfatórias ao volume de demandas do Projeto.

Todavia, não há como limitar o entendimento do problema apenas a tais dimensões, como grande parte dos atores envolvidos e consultores contratados pensavam. O fator gerenciamento ${ }^{4}$ de um Projeto é um aspecto fundamental a ser observado, não somente quando se trata de definir as ações voltadas à sua implementação, como também quando se pretende investigar o processo em curso. Mas isso não é tudo, ou nem tudo que acontece e se desencadeia no contexto de uma organização ou de um conjunto organizado de relações formal e legalmente instituídas pode ser interpretado apenas pelo viés do gerenciamento, embora esse aspecto seja importante, já que inerente à própria dinâmica de um universo organizacional.

Há dimensões submersas, esquecidas, como acentua Chanlat (1996) e muitas vezes invisíveis nesse mundo tão rigorosamente planejado, aparentemente previsível e organizado, as quais não necessariamente estão relacionadas a programas de ação, à estrutura material, a comandos eficientes, controles precisos e coordenação

\footnotetext{
$4 \quad$ O termo gerenciamento é comumente utilizado para fazer referência a um conjunto de ações relacionadas ao ato de administrar, ou ao campo da administração. Na literatura consultada, os dois termos - gerenciamento e administração - não surgem como sinônimos nas diversas teorias administrativas analisadas. Tudo leva a crer, entretanto, que, a despeito das variações encontradas em cada teoria, aquilo que é definido como função administrativa engloba aquilo que o gerenciamento supõe.
} 
Artigo original

Hegemonia - Revista Eletrônica de Relações Internacionais do Centro Universitário Unieuro

ISSN: 1809-1261

UNIEURO, Brasília, número 7, 2011, pp. 52-72.

eficaz de todos os atos e esforços coletivos. Daí a importância do olhar - crítico - do antropólogo.

Um dos momentos em que foi possível constatar a importância desse olhar foi durante um dos processos de avaliação do desempenho do Projeto - a Avaliação de Meio Termo do Projeto prevista para acontecer após um determinado período de execução das ações programadas. Conforme ressaltei em trabalhos anteriores (Lima, 2000), como parte de seu objetivo de se repensar e de se reinventar a partir da experiência, o Projeto investiu em várias estratégias e metodologias de monitoramento e de avaliação das ações desenvolvidas.

Assim, durante três dias, cerca de cinqüenta pessoas se reuniram no intuito de repensar as ações do PPTAL e a fim de levantar subsídios para fundamentar a Avaliação de Meio Termo ${ }^{5}$ : enfim, uma verdadeira performance que produziu uma seqüência de atos simbólicos, revelando hierarquias, formas de classificar o mundo e também contradições.

O que me chamou a atenção, no primeiro dia, foram os diferentes enfoques dos problemas do PPTAL, quando abordados por olhares marcados por distintas tradições representadas pelas abordagens produzidas pelos dois consultores independentes (um antropólogo e um administrador, externos ao PPTAL), cujo trabalho consistiu em avaliar o Projeto nos âmbitos temático e gerencial.

Certamente o fato de se contratar um antropólogo e um administrador para uma avaliação do desempenho de um Projeto está assentado na premissa de que este comporta dimensões que, embora 
Artigo original

Hegemonia - Revista Eletrônica de Relações Internacionais do Centro Universitário Unieuro

ISSN: 1809-1261

UNIEURO, Brasília, número 7, 2011, pp. 52-72.

conectadas, atuam separadamente e não se misturam para fins de monitoramento e planejamento. São dimensões que devem, portanto, receber um tratamento próprio, orientado por uma linguagem e um olhar que trazem embutidos uma semântica particular e um modo também particular de ver as coisas.

Enquanto o antropólogo falava em participação indígena, o administrador falava em organização matricial; enquanto o antropólogo mencionava a ausência dos interlocutores "em carne e osso"; o administrador mencionava a ausência de comitê de gerenciamento. Tais ênfases expressavam distintos processos disciplinadores do olhar, do ouvir e, finalmente, do escrever, para relembrar as formulações de Cardoso de Oliveira (1998) sobre o trabalho do antropólogo. Além disso, o destaque dessas duas abordagens - gerencial e técnica/temática - como primeiro passo conduzido na avaliação de um projeto e carro-chefe na abertura do evento veio demonstrar a importância, naquele contexto e para aqueles agentes, daquelas distinções e a necessidade de reforçá-las.

Assistimos, portanto, naquele confronto de linguagens, a um conjunto de visões e divisões sendo reproduzido e acentuado por um ritual voltado também para prescrever com nitidez um lugar para cada coisa e uma coisa para cada lugar. (Da Matta, 1987). Se tal não ocorresse, isto é, se a separação dos campos não fosse demonstrada conforme uma certa lógica pela qual estamos acostumados a ordenar o mundo para melhor compreendê-lo, classificá-lo e controlá-lo, então teríamos tudo, menos avaliações consistentes, fundamentadas e confiáveis. Nesse sentido, aquele ritual não foi efetuado apenas para avaliar o PPTAL, mas também para confirmar posições, hierarquias, distinções e diferentes formas de analisar a realidade, 
Artigo original

Hegemonia - Revista Eletrônica de Relações Internacionais do Centro Universitário Unieuro

ISSN: 1809-1261

UNIEURO, Brasília, número 7, 2011, pp. 52-72.

segundo campos discursivos que nos vem ensinando a eficácia de ver, decifrar e reconstruir o mundo de forma compartimentada.

Além disso, durante os dias em que o evento foi produzido, a condução da metodologia de trabalho, com suas performances e ritos particulares, deu visibilidade às diversas contradições e limitações que perpassavam o Projeto. A questão da participação indígena, por exemplo, tão enfatizada nos textos e discursos oficiais, na verdade se esmaecia diante do vigor das hierarquias, de certos lugares de fala e das posições de determinados agentes. Assim, naquele evento transparecia a debilidade do Projeto em criar estratégias reais de participação que possibilitassem aos índios presentes construir o seu próprio lugar de fala em meio a tantos parceiros que procuravam falar em seu lugar. Era como se ali, em meio a diversos confrontos de posições e argumentos, inúmeros power points, fichinhas e sínteses a fragmentar objetivos, problemas e soluções, os participantes indígenas não encontrassem o seu lugar, dentro daquele campo de sínteses e racionalidade. Ou seja, com raras exceções, os maiores interessados permaneceram numa postura quase contemplativa, sem alcançar a proclamada posição de interlocutores num processo que traçava rumos para suas próprias vidas.

Em outro momento do Projeto, em que fui particularmente envolvida para coordenar o desenho final de um dos Componentes Vigilância e Fiscalização - novamente o meu olhar pode constatar não só a debilidade do Projeto em criar estratégias e mecanismos concretos de participação indígena, como também os limites que foram impostos a minha atuação como antropóloga.

A idéia era a de deixar claro que o Projeto não concebia a vigilância como mera fiscalização e exercício de poder de polícia sobre as terras indígenas, mas como uma forma de engendrar ações que contribuíssem para a sustentabilidade das terras demarcadas e para 
Artigo original

Hegemonia - Revista Eletrônica de Relações Internacionais do Centro Universitário Unieuro

ISSN: 1809-1261

UNIEURO, Brasília, número 7, 2011, pp. 52-72.

o efetivo controle territorial por parte dos índios. Tudo dentro de um processo participativo que previa o envolvimento das comunidades desde a concepção e planejamento, até a execução dos planos de vigilância traçados.

Solicitaram-me nesse sentido que elaborasse um esboço de proposta que deveria ser encaminhada à cooperação alemã-GTZ e ao Banco Mundial-BIRD para avaliação. Para tanto, procurei construir uma interlocução com algumas lideranças indígenas para informá-las sobre a concepção do Projeto acerca do componente, e também para ouvir e incorporar, no desenho da proposta, suas concepções sobre vigilância e fiscalização. Ressalto que tudo o que os representantes indígenas propuseram como estratégia foi explicitado no texto da proposta. Todavia, nada foi incorporado ao documento final, assim como fui repreendida por ter atropelado a hierarquia, conversando com os índios antes de conhecer a proposta da GTZ.

Acrescento que esse processo de redesenho do componente junto com a GTZ revelou-se extremamente tenso, já que a cooperação alemã tinha em mente contratar os serviços de uma ONG - os Amigos da Terra - para implantar um serviço de radiofonia em algumas comunidades, a fim de habilitar um sistema de comunicação mais eficiente entre elas. Embora sua argumentação fosse aceita, as discordâncias e conflitos surgiram a partir do momento em que houve a suposição de que a GTZ, sem procurar ouvir e inserir os índios nesse processo, tinha como objetivo investir em uma única estratégia de vigilância e, sobretudo, beneficiar a ONG previamente escolhida. Assim, o capítulo do componente foi encerrado com a contratação da referida ONG, sem que outras estratégias de vigilância, definidas com a participação indígena, fossem ao menos discutidas. No que se refere a minha atuação como antropóloga e a minha tentativa de construir uma interlocução com os índios, o resultado foi frustrante. 
Artigo original

Hegemonia - Revista Eletrônica de Relações Internacionais do Centro Universitário Unieuro

ISSN: 1809-1261

UNIEURO, Brasília, número 7, 2011, pp. 52-72.

Em suma, a experiência dessa consultoria propiciou-me um olhar crítico que pode ser incorporado para enriquecer experiências posteriores. Esse olhar somente se produziu porque, a partir da antropologia, fui sensibilizada para ver o mundo de uma certa maneira. Porque ouvi e aprendi que há formas de repensar o mundo mediante a reconstrução de certos espaços, relações e eventos incluindo, workshops, seminários, oficinas de avaliação, missões de supervisão - como rituais que buscam confirmar e reforçar posições e hierarquias. Porque aprendi que o meu ofício envolve o exercício da interlocução e da mediação, cujo desenvolvimento requisita um certo olhar, um certo ouvir e um certo escrever, como argumentou Cardoso de Oliveira (1998) em suas análises sobre o trabalho do antropólogo.

\section{Sobre o "Mapeamento das Populações Extrativistas da Amazônia Legal"}

Ao longo dessas duas últimas décadas, várias iniciativas foram empreendidas no âmbito do governo federal brasileiro, por intermédio do Ministério do Meio Ambiente e de várias modalidades de cooperação - internacional e interinstitucional, bem como técnica e financeira - com o objetivo de contribuir para a formulação de políticas públicas voltadas para o fortalecimento do agroextrativismo e dos grupos que integram o setor na Amazônia. Tais iniciativas tinham como motivação a idéia de que determinadas formas de extrativismo são práticas de produção e de sobrevivência não predatórias que, se apoiadas econômica, jurídica, técnica e politicamente, propiciariam benefícios tanto ambientais como sociais. 
Artigo original

Hegemonia - Revista Eletrônica de Relações Internacionais do Centro Universitário Unieuro

ISSN: 1809-1261

UNIEURO, Brasília, número 7, 2011, pp. 52-72.

Assim, parcerias institucionais, pesquisadores, técnicos e representantes do setor extrativista foram mobilizados para, numa combinação de esforços, gerarem idéias e ações que viabilizassem um salto qualitativo no tratamento da questão. Dentre essas iniciativas, foi prevista a elaboração de um mapeamento das populações agroextrativistas da Amazônia, no sentido não só de localizá-las no seu vasto território, mas também de tentar identificar suas principais demandas e dificuldades.

O Instituto Socioambiental-ISA - organização-nãogovernamental que, há décadas, desenvolve trabalhos na área de meio ambiente e com populações indígenas e tradicionais - foi a instituição indicada para construir essa base de informações a partir da qual seriam formuladas políticas futuras para o setor. Assim, no início de 2001, o MMA, por meio de sua Secretaria de Coordenação da Amazônia-SCA, e o ISA celebraram um convênio para dar início ao projeto de pesquisa “Mapeamento das Populações Extrativistas da Amazônia".

As atividades propostas para esse trabalho previram: a criação de um Banco de Dados que registrasse e organizasse informações sobre os grupos extrativistas da Amazônia Legal; o levantamento de suas demandas junto ao MMA, com base nas linhas de financiamento desse órgão; o levantamento das iniciativas voltadas para o fortalecimento do extrativismo sustentável junto aos órgãos públicos e setores não governamentais; o aprimoramento gradativo do Banco, com a qualificação dos dados via pesquisa de campo e contatos com as organizações sociais.

Um dos objetivos centrais definidos no Convênio - a criação, pelo ISA, do Banco de Dados para registrar e organizar informações sobre os grupos extrativistas - representou o próprio ponto de 
Artigo original

Hegemonia - Revista Eletrônica de Relações Internacionais do Centro Universitário Unieuro

ISSN: 1809-1261

UNIEURO, Brasília, número 7, 2011, pp. 52-72.

partida do trabalho. O Banco foi estruturado com entrada para cadastramento de projetos de apoio já existentes e entrada para cadastramento das organizações localizadas. Assim, por um período e contrato de um ano, atuei como coordenadora da pesquisa sobre grupos extrativistas da Amazônia, que daria suporte do referido mapeamento.

As dificuldades começaram a surgir a partir da constatação não só do volume de trabalho representado pelo cadastramento, como também em virtude do próprio entendimento, pelos agentes governamentais e não-governamentais envolvidos, do significado de uma pesquisa que, embora não acadêmica, deveria se basear em uma determinada metodologia e critérios de controle.

Ademais, era curioso perceber $o$ quanto a questão do pertencimento pode gerar problemas de interlocução e a negação do passe de entrada do pesquisador - e a obtenção de informações - em determinados contextos. Ali, eu não era Estado, nem muito menos ONG, nem parte da sociedade civil organizada em torno do extrativismo. Era apenas uma consultora em antropologia contratada para realizar uma pesquisa, cujos objetivos muitos não compreendiam e até questionavam. Todavia, em cada contexto pesquisado ou campo recortado para levantamento de informações, uma reinterpretação do meu papel e lugar de fala eram providenciados.

Ressalto que, nos trabalhos que envolvem parcerias interinstitucionais entre representantes do Estado e do Terceiro Setor, é comum a definição de fronteiras recíprocas entre os que são Estado e os que são ONG. Tais fronteiras se erguem por razões que nesse trabalho não pretendo explorar, mas que podem constituir obstáculos para o bom exercício da parceria, da cooperação e dos 
Artigo original

Hegemonia - Revista Eletrônica de Relações Internacionais do Centro Universitário Unieuro

ISSN: 1809-1261

UNIEURO, Brasília, número 7, 2011, pp. 52-72.

processos participativos. Enfim, embora me apresentasse diante de todos da forma mais independente possível, ainda que com vínculo contratual temporário e preciso do ponto de vista institucional, tanto com o ISA quanto com o MMA, a questão do pertencimento sempre vinha à tona, muitas vezes para dificultar o trabalho.

No âmbito do Estado, em ministérios, secretarias e autarquias visitadas, era comum me identificarem com o ISA, o que, por vezes, gerava desconfianças: "Ah, você é a pesquisadora do ISA? E o que o ISA pretende com essas informações?" No contexto da sociedade civil organizada em torno do extrativismo, lideranças e grupos locais viam-me como Estado e, como representante do Estado, eu era associada a um pacote que reunia sempre técnicos e projetos freqüentemente bem intencionados, mas ineficazes.

Além disso, o grande volume do material documental a consultar - e da minha solidão para fazê-lo - tornou imprescindível a reavaliação da metodologia praticada, tendo em vista os prazos acordados e as metas delineadas. A localização de grupos e mapeamento de suas demandas via análise de projetos e programas já existentes, no âmbito governamental e não-governamental, tornava o trabalho lento, na medida em que isso dependia de outras agendas e rotinas institucionais, bem como exigia a montagem de uma equipe maior para imprimir um ritmo mais veloz à triagem e consulta do material. Quanto à constituição de um grupo de pesquisa que, sob minha orientação, poderia agilizar o processo de levantamento, consulta, análise e cadastramento de dados, não houve o entendimento de que isso seria necessário.

Procurei ainda: estreitar contatos com atores específicos (ONGs de apoio ao setor e representantes de organizações extrativistas); constituir uma mala direta para obtenção de informações e participar 
Artigo original

Hegemonia - Revista Eletrônica de Relações Internacionais do Centro Universitário Unieuro

ISSN: 1809-1261

UNIEURO, Brasília, número 7, 2011, pp. 52-72.

em eventos (seminários e encontros) com representantes do setor e criar uma rede de colaboradores a partir do diálogo com diversos representantes do segmento e com aqueles que pesquisam e atuam no âmbito do extrativismo. Por fim, tentei demonstrar que algumas dificuldades poderiam ser sanadas, tais como: a de alcançarmos, de Brasília, grupos de menor ou nenhuma visibilidade, cujo surgimento e retraimento - se dá numa dinâmica de impossível controle; a de estendermos e aplicarmos questionários preparados para uma qualificação mais adequada dos dados àqueles grupos e comunidades que não estivessem institucionalmente organizados. Além disso, procurei argumentar que a criação de um grupo de colaboradores dentro de próprio universo das organizações representativas do segmento agroextrativista propiciaria o seu envolvimento com a produção do conhecimento sobre o seu próprio mundo. Reuniões envolvendo todos os parceiros dessa pesquisa para avaliação dos produtos solicitados seriam organizadas periodicamente em campo.

Apesar de minhas insistentes sugestões como pesquisadora orientada pelo meu olhar antropológico - que buscava construir a interlocução, antes de tudo, com os maiores interessados ou beneficiários das políticas que resultariam do conhecimento gerado pela pesquisa - pouco foi aproveitado. O trabalho, com todas as limitações e obstáculos constituídos em sua realização, efetuou apenas o levantamento, junto às mais diversas fontes, de projetos e programas de apoio ao setor, bem como das organizações extrativistas da Amazônia localizadas pelo mapeamento para a sua inserção no Banco de Dados. Ao final, conseguimos cadastrar 971 entidades que atuam na Amazônia, dentre associações extrativistas, cooperativas, conselhos, sindicatos, federações, instituições 
Artigo original

Hegemonia - Revista Eletrônica de Relações Internacionais do Centro Universitário Unieuro

ISSN: 1809-1261

UNIEURO, Brasília, número 7, 2011, pp. 52-72.

governamentais e não-governamentais, instituições de pesquisa, organizações indígenas e indigenistas, etc.

\section{Considerações Finais}

Para concluir, considero que, fora do campo acadêmico, ou como consultor, gestor ou técnico dentro de outros campos, é possível, em vários momentos, assumir a postura do antropólogo no sentido de procurar compreender problemas, encaminhar negociações, manejar diferenças e, sobretudo, enxergar o outro e, assim, respeitá-lo e pensá-lo como interlocutor e não apenas como alvo das intervenções de cooperadores e parceiros, ainda que movidos pelas melhores intenções.

O conhecimento do campo dentro do qual atuamos nos permite demonstrar nossa habilidade em evidenciar lógicas que, orientadas por distintas visões de mundo, geram conflitos que exigem mediações. Contudo, se essa capacidade de mediação é aprendida nos exercícios de desnaturalização constitutivos do fazer antropológico, nas assessorias e consultorias que realizamos ela é permanentemente testada e, por vezes, dispensada diante dos imperativos institucionais. Ficamos, como concluiu Silva, "como profissionais que descrevem um ziguezague entre campos diferentes, em que operam lógicas diferentes, bem como formas de reconhecimento e de legitimação diferenciadas" (2008: 16)

Isso constitui, no meu entender, um dos impasses vividos pelos antropólogos quando inseridos em contextos profissionais não acadêmicos. Ao mesmo tempo em que observamos o mundo com o olhar do antropólogo - o que representa um diferencial na abordagem de certos temas e problemas - ocupamos, nesses 
Artigo original

Hegemonia - Revista Eletrônica de Relações Internacionais do Centro Universitário Unieuro

ISSN: 1809-1261

UNIEURO, Brasília, número 7, 2011, pp. 52-72.

contextos, um lugar institucional que impõe certos limites às nossas ações. Somos capazes de participar observando, ou de observar participando, mas não estamos apenas diante de cadernos de campo e de sujeitos com os quais buscamos construir uma interlocução, preservando autonomias e direitos.

Estamos também diante de profissionais orientados por outras formações. Estamos diante de equipes, colaboradores e da necessidade de agir, decidir, negociar agendas, conciliar interesses e produzir relatórios em tempos precisos e prazos exigidos. E assim, embora o antropólogo que somos não desapareça e permaneça com o seu olhar e princípios, somos devolvidos à agenda do campo, onde, por vezes, melancolicamente, presenciamos o esquecimento de nossas recomendações...

\section{Bibliografia}

CHANLAT, Jean-François. "Por uma antropologia da condição humana nas organizações." In: O indivíduo na organização: dimensões esquecidas. Chanlat,J ean-François (coord.) São Paulo: Atlas, 1996.

CLEGG, Stewart. "Poder, linguagem e ação nas organizações". In: O indivíduo na organização: dimensões esquecidas. Chanlat, JeanFrançois (coord.). São Paulo: Atlas, 1996.

DA MATTA, Roberto. A Casa e a Rua. Espaço, cidadania, mulher e morte no Brasil. Rio de Janeiro: Ed. Guanabara, 1987.

LIMA, Ludmila M. Se a Funai não faz, nós fazemos. Tese de Doutorado. Programa de Pós-Graduação em Antropologia Social. Depto de Antropologia. Universidade de Brasília.2000. 
Artigo original

Hegemonia - Revista Eletrônica de Relações Internacionais do Centro Universitário Unieuro

ISSN: 1809-1261

UNIEURO, Brasília, número 7, 2011, pp. 52-72.

“Retrospectiva das atividades desenvolvidas no

contexto da pesquisa Mapeamento das populações Extrativistas da Amazônia Legal." In: Esterci, E., Lima, D. \& Léna, P. Rede Amazônia:Diversidade Sociocultural e Políticas Ambientais. Rio de Janeiro: Ed. In-Fólio. Ano 1, no1,2002.

OLIVEIRA, Roberto Cardoso de. O trabalho do antropólogo. São Paulo: Unesp, 1998.

SILVA, Gláucia. “Apresentação". In: SILVA, G. (org.) Antropologia extramuros:novas responsabilidades sociais e políticas dos antropólogos. Brasília: ABA/Ed.Paralelo 15, 2008. 